\title{
Urban Trees and Water: An Overview of Studies on Irrigation Needs in the Western United States and a Discussion Regarding Future Research
}

\author{
Laurence Costello
}

\begin{abstract}
A review of the literature concerning water needs and water loss from landscape plants is presented. Studies conducted in the field, using lysimeters, and in containers are summarized and discussed. In some studies, crop coefficients or water use coefficients are included. A discussion of the variability found in research methods and the need for a standardized protocol for tree water needs studies is presented.

Key Words. Crop Coefficients; Irrigation; Lysimeter; Plant Water Loss; Reference Evapotranspiration; Tree Water Needs; Urban Trees; Water Conservation.
\end{abstract}

This report provides an overview of studies that have evaluated the performance of urban trees under differing levels of irrigation, and summarizes findings that can be used to help determine tree water needs. Papers that measure water loss from tree crowns are included, although they do not necessarily provide an assessment of water needs. The scope of studies is limited to work conducted in the western United States, including the states of California, Nevada, Arizona, Utah, Colorado, and New Mexico. These states receive little precipitation in the summer months and water management for urban vegetation is of paramount importance. The focus is on urban trees, but other types of vegetation are included, such as shrubs and ground covers. For an extensive listing of literature on landscape water conservation and management topics prior to 1995 , see Santos and Burger (1995). They include nearly 1,300 citations of books, articles, and manuals that address design, construction, and maintenance issues related to small and large commercial landscapes, small and large residential landscapes, and public works. For a more recent review of the literature on efficient landscape irrigation, see Hilaire et al. (2008). Thirteen authors from 11 different academic institutions in six U.S. states contributed to this paper that summarizes how the following factors impact the efficient use of water in urban landscapes: irrigation and water application technologies, design and management strategies, reuse of water resources, social considerations, incentives (economic and noneconomic), and public policy. Similarly, Kjelgren et al. (2000) address key issues associated with water use and conservation in landscapes: plant water needs, irrigation system uniformity, conservable water, and methods of conservation and their implementation.

In order to group studies similar in nature, reports have been sorted first according to vegetation type: 1) trees and 2) other plant types. Tree studies are then separated into two categories: 1) studies conducted in the field, and 2) studies conducted in containers or lysimeters. For studies conducted in the field, both broadleaf species and palms are included. From a management perspective, studies evaluating tree performance following irrigation treatments are of greatest interest because they provide guidance regarding how much water may be needed to maintain a species in good condition.

\section{TREES}

\section{Field Studies}

Very few field studies have been conducted evaluating water needs of urban trees in the western U.S. Only three studies are reported here, two for broadleaf species and one for palms.

Most recently, Schuch et al. (2010) evaluated the performance of nine tree species commonly planted in the low desert of Arizona. Trees were planted in field plots and established for 19 months prior to the initiation of three irrigation treatments: available soil moisture in the root zone was depleted by $30 \%, 50 \%$, and $70 \%$. Twelve months after treatments began, no differences in tree height, caliper, or growth index were found for seven species, while two species receiving the lowest irrigation treatment (70\% depletion) showed signs of water stress. Overall quality of all trees was rated as being good based on an assessment of visual appearance. Note that this is an ongoing study and only first-year results have been reported.

Costello et al. (2005) evaluated the growth response of three California native oak species to three irrigation levels $(0 \%$, $25 \%$, and $50 \%$ evapotranspiration, or ETo) in Santa Clara, CA. Container-grown trees were planted into a cultivated loam soil and irrigated uniformly during a one-year establishment period. After a four-year treatment period, no significant differences in trunk caliper were found for any of the irrigation treatments for all three species (Quercus agrifolia, Q. lobata, and $Q$. douglasii). 
Basically, tree growth and visual appearance for trees receiving no irrigation were not different from those receiving $25 \%$ or $50 \%$ of reference ETo. Average annual rainfall at the study site is $40.6 \mathrm{~cm}$.

To assess the effect of irrigation level on the performance of palm species, Pittenger et al. (2009) conducted a study in Irvine, CA. Five landscape species (Archontophoenix cunninghamiana, Chamaerops humilis, Syagrus romanzoffiana, Trachycarpus fortunei, and Washingtonia filifera) were irrigated at three levels of reference ETo: $0 \%, 25 \%$, and $50 \%$. All species maintained at least minimally acceptable visual quality at the 0\% ETo treatment (no irrigation), and two species were found to have near optimum performance with no irrigation, while two species produced more leaves with additional irrigation. The authors note that the water needs of landscape palms are considerably less than that those of commercial palms, such as date, oil, and coconut palms.

\section{Container or Lysimeter Studies}

To measure tree water use and/or determine species water needs, a number of studies have been conducted using plants in containers or lysimeters. Here, studies are sorted into two groups depending on whether plant water supply was limited or not.

\section{Water supply limited}

In these studies, experimental design included treatments where the supply of available water was limited to some extent. In a two-year study, Devitt et al (1994) measured water loss from three landscape species in Las Vegas, NV. Three container stock sizes (3.8, 18.9, and 56.8 L) of Prosopis alba, Chilopsis linearis, and Quercus virginiana were planted into 190-liter lysimeters. After a three-month establishment period, three irrigation treatments were imposed as leaching fractions of $+0.25,0$, and -0.25 (drainage volume/irrigation volume). Although water loss from species (ETa) was affected by tree size and leaching fraction treatments, there was little or no effect of irrigation level on trunk diameter growth.

In a similar study, Devitt el al. (1995) measured water loss from three tree species (Washingtonia robusta, Pinus eldarica, and Cercidium floridum) planted as container stock (\#5 and \#15) into 190-liter lysimeters. Treatments were similar to Devitt et al. (1994) with irrigation levels expressed as leaching fractions of $+0.25,0$, and -0.25 . After a three-month establishment period, treatments were imposed for a six-month period. Althoughsignificant differencesinwateruse were found for species resulting from planting size and leaching fraction (irrigation level), no significant effect on canopy volumes or basal canopy areas were found, and few significant differences in trunk diameter were found across irrigation treatments for all species.

\section{Water supply not limited}

In these studies, experimental design did not include treatments where the supply of available water was limited to some extent (i.e., water was continuously available to the plant).

In a three-month study, Levitt et al. (1995) measured water loss from Prosopis alba (Argentine mesquite) and Quercus virginiana (southern live oak) growing in containers in Tucson, AZ. A gravimetric method was used to determine actual plant water loss, and water-use coefficients were cal- culated as the ratio of water loss to reference evapotranspiration for the study site. Water-use coefficients of 0.5 for southern live oak and 1.0 for mesquite were reported using water loss values for the total leaf area, and 1.4 (oak) and 1.6 (mesquite) for water loss on a projected canopy basis.

To determine water needs of balled and burlapped (B\&B) stock during the first year after planting in a semi-arid climate, Montague et al. (2004) conducted a one-year study in Logan, UT. The performance of five species (Platanus $\times$ acerifolia, Salix matsudana, Tilia cordata, Acer platanoides, and Fraxinus pennsylvanica) was evaluated using locally grown field stock planted into lysimeters. Water loss was measured from trees under nonlimiting conditions, and a water loss coefficient (Kc) was calculated as the ratio of actual water loss (based on total leaf area) to total daily ETo. Tree water loss varied with species, and water loss coefficients ranged from 0.19 for A. platanoides to 1.05 for $S$. alba.

To quantify the influence of shading on water loss, Costello et al. (1996) conducted a study using container plants in Palo Alto, CA. Three tree species (Sequoia sempervirens, Magnolia grandiflora, and Liquidambar styraciflua) and one shrub species (Pittosporum tobira) were placed in full sun (86,000 lux) or a shaded environment (820 lux) and water loss was measured gravimetrically over a two-week period. Plants in the shaded environment were found to lose on average $58 \%$ less water than those in the full sun environment.

\section{OTHER PLANT TYPES (GROUND COVERS, SHRUBS, AND HERBACEOUS PLANTS)}

\section{Field Studies}

In a relatively early report, Sachs (1991) conducted a two-year study at two sites in California (San Jose and Irvine), evaluating the performance of hedgerow and ground cover plantings irrigated at $0 \%, 12.5 \%$, and $100 \%$ ETo. Species included were Ligustrum lucidum, Pittosporum tobira, Nerium oleander, Coprosma baueri, Xylosma congestum, Eugenia uniflora, Hedera canariensis, and Carpobrotus sp. Plantings were established in 1965 and treatments were initiated six years later (1971). At both study sites, an irrigation level of approximately $12.5 \%$ ETo was sufficient to maintain all plants in a healthy condition with good appearance. Higher amounts of water caused increasing amounts of growth, which also increased their pruning requirements.

A two-year study to assess the performance of three groundcover species irrigated at $0 \%, 25 \%, 50 \%, 75 \%$, and $100 \%$ of ETo was initiated in 1991 by Staats and Klett (1995). A principal goal of the study was to identify water-conserving species that could serve as alternatives to Kentucky bluegrass (Poa pratensis). They reported that an optimum irrigation level for Cerastium tomentosum and Sedum acre was $25 \%$ ETo (after becoming established), while Potentilla tabernaemontii required 75\% ETo.

In 1990, Pittenger et al. (2001) initiated an evaluation of the performance of six groundcover species at four irrigation levels: $20 \%, 30 \%, 40 \%$, and 50\% ETo. All species had been established for a one-year period in 1989 at 25\%, 50\%, $75 \%$, and $100 \%$ ETo (Pittenger et al. 1990). After a 17-month treatment period, they reported that Drosanthemum hispidum, Baccharis pilularis, and Hedera helix performed well at $20 \%$ ETo, while Vinca major required 30\%. Both Potentilla tabernaemontii and Gazania sp. were found to need greater than 50\% ETo. 
In 1996, Shaw and Pittenger (2004) evaluated the performance of 30 species of shrubs in Encinitas, CA. Following an establishment period of approximately 18-months, plants were irrigated for one year at 12\%, 24\%, and 36\% ETo, while in 1997 and 1998 irrigation treatments were adjusted to $0 \%, 18 \%$, and $36 \%$ of ETo "because initial treatments were not affecting plant quality." Irrigation frequency was determined using a projected soil moisture deficit of $13 \mathrm{~mm}$. The authors reported that "many species performed well at $36 \%$ and $18 \%$ ETo treatments, but suffered at 0 ETo." Eight shrub species performed well with no irrigation, while 13 species performed well at $18 \%$ ETo. Three species did not become established in the study plot, and the remaining species required irrigation levels greater than $18 \%$ ETo.

In an evaluation of herbaceous species, Reid and Oki (2008) conducted a one-year study in Davis, CA. After a one-year establishment period in 2005, six species of California native plants were irrigated at four irrigation levels: $20 \%, 40 \%, 60 \%, 80 \%$ ETo. Plant performance was evaluated using a growth index. For all six species, no significant differences in summer growth or physical appearance were found for the four irrigation levels. Ongoing performance evaluations of the same species are being conducted in seven climate zones throughout California.

\section{Container and Lysimeter Studies}

Using both containers and lysimeters, Garcia-Navarro et al. (2004) measured the water use of four shrub species in Davis, CA. After a one-year establishment period, two parallel experiments (using containers and lysimeters) were conducted during the summer of 1998. The authors state that "the relative water use of the same species in 3.8-liter containers would be representative of the water use of the same species in the landscape." Lysimeter plants were irrigated at $30 \%$ and $100 \%$ of ETo, while container plants received either daily irrigation or water was withheld until available water was depleted. Crop coefficients for the well-irrigated container plants (all four species) were found to range from 1.30 to 5.51, while three species showed a three-fold reduction in water use when water-stressed. At 30\% ETo, water use was reduced by $52 \%$ to $55 \%$ for plants in lysimeters (three species). Growth of all species was affected by reduced irrigation, and visual appearance declined substantially for two species.

\section{DISCUSSION}

From the results of field studies, water needs assessments were found to vary according to vegetation types and species. For trees, seven species of arid-adapted trees were reported to perform well under a $70 \%$ soil water deficit treatment, while two species performed better at a 50\% depletion level (Schuch et al. 2010). Oaks receiving no irrigation performed as well as the same species receiving 25 and 50\% ETo (Costello et al. 2005). Similarly, two palm species were found to perform optimally at $0 \%$ ETo, while three others were assessed as having acceptable quality without irrigation (Pittenger et al. 2009).

Field studies of other vegetation types show a somewhat wider range of species water needs. An irrigation level of $12.5 \%$ ETo was found to be sufficient for eight hedgerow and groundcover species (Sachs 1991); while in another study (Staats and Klett 1995), two groundcover species performed well at 25\% ETo, yet one species needed $75 \%$ ETo). For shrubs, eight species were reported to perform well at $0 \%$ ETo, while another 13 species required an irrigation level between $18 \%$ and 36\% ETo (Shaw and Pittenger 2004). In a study evaluating six herbaceous species, all species performed well at 0\% ETo (Reid and Oki 2008).

In lysimeter studies where water supply was limited, no effect of reduced irrigation was found on trunk diameter growth for three species of trees (Devitt et al. 1994). In a follow-up study by Devitt et al. (1995), similar results were found for an additional three species of trees. In a container and lysimeter study where water supply was limited for four shrub species, water use reductions resulted in growth reductions for all species and a decline in visual appearance for two species.

In a lysimeter study where water supply was not limited (Levitt et al. 1995), water-use coefficients were found to range from 0.5 to 1.0 for two tree species (based on a total leaf area) and from 1.4 to 1.6 (based on a projected canopy). For B\&B stock planted into lysimeters, water-use coefficients ranged from 0.19 to 1.05 for five tree species.

Collectively from field and lysimeter studies, many of the woody and herbaceous species evaluated were found to perform well at irrigation levels less than $25 \%$ ETo. Indeed, a number of species were found to perform well without irrigation (0 ETo). These findings are important for landscapes in climate zones where precipitation is limited during the year, such as in arid, semi-arid, and Mediterranean zones. The use of landscape species that require little or no irrigation once established will be of great value in creating and maintaining water-conserving landscapes.

Certainly, a considerable amount of research still needs to be done. For instance, evaluations for only 17 tree species are reported in this review. Clearly, this number is not sufficient to provide useful guidance regarding the water needs of landscape species. For trees in particular, much more research is needed to identify the needs of the hundreds of species used in urban forests in the western U.S. In addition and most importantly, a standardized protocol for conducting such research is critically needed. From this review, it is evident that a substantial level of variation exists in experimental design and methods. For the species evaluated, many differences can be found in treatment levels, methods for quantifying water supplied to individual plants, use of soil moisture measurements to schedule irrigations, length of establishment and treatment periods, stock types, irrigation systems used, and measures of plant performance. These are critical elements of an experimental design that affect the outcome of waterneeds studies, making it difficult to compare study results. This leads to an important question: What is the best method of conducting water-needs studies? Unfortunately, as yet, there is no standardized method-but one needs to be established.

A number of other questions regarding experimental methods used for water-needs evaluations of trees can be listed:

- What are reasonable levels of ETo for treatments? Certainly, no irrigation ( $0 \%$ ETo) should be included, but what amounts should be used for irrigation levels (10\%, $30 \%$, and $50 \% \mathrm{ETo}$ )?

- What is the best way to determine the amount of water that matches the desired level of reference evapotranspiration? For example, how much water should be applied to a $2.5 \mathrm{~cm}$ caliper tree for $50 \%$ ETo? How much for a $5 \mathrm{~cm}$ caliper tree? What irrigation frequency should be used? 
- What is a reasonable period for irrigation treatments? Should they last for $1,2,3,4$, or more years? What is a reasonable period for plant establishment? In the studies reviewed, establishment periods ranged from three months to six years.

- Which performance parameters or variables are most relevant to the scientific community? Is it most meaningful to measure shoot elongation, crown size, trunk diameter, and/or leaf area? Certainly, physiological parameters such as stomatal conductance, leaf temperature, and/or water potential should be considered where possible. In landscapes, plant aesthetics is an important performance parameter to assess, but a standardized method of quantification is needed to maintain consistency across studies and allow comparative analyses of species performance.

- Can results from trees with confined root zones, such as lysimeter and container studies, be applied to the field management of trees? Do limitations in soil volume (relative to field conditions) affect water needs? Even though root systems have more volume for growth in lysimeters compared to containers, they are still limited compared to field conditions. For instance, Schuch and Burger (1997) found water-use and crop coefficients of woody plants in containers varied considerably among species, location, and time of year.

These and other questions need to be addressed in order to establish a dependable protocol for evaluating the water needs of trees. With such a standardized approach, a consistency in methods will be maintained from one study to another, and results will be readily comparable.

\section{LITERATURE CITED}

Costello, L.R., K.S. Jones, and D.D. McCreary. 2005. Irrigation effects on the growth of newly planted oaks (Quercus spp.). Journal of Arboriculture 31(2):83-88.

Costello, L.R., D. Thomas, and J. DeVries. 1996. Plant water loss in a shaded environment: A pilot study. Journal of Arboriculture 22(2):106-108.

Devitt, D.A., D.S. Neuman, D.C. Bowman, and R.L. Morris. 1995. Water use of landscape plants in and arid environment. Journal of Arboriculture 21(5):239-245

Devitt, D.A., R.A. Morris, and D.S. Bowman. 1994. Evapotranspiration and growth response of three woody ornamental species placed under varying irrigation regimes. Journal of the American Society of Horticultural Science 119(3):452-457.

Garcia-Navarro, M.C., R.Y. Evans, and R.S. Monsterrat. 2004. Estimation of relative water use among ornamental landscape species. Scientia Horticulturae 99(2004):163-174.

Hilaire, St. R., M. Arnold, D.C. Wilkerson, D.A. Devitt, B.H. Hurd, B.J. Lesikar, V.I. Lohr, C.A. Martin, G.V. McDonald, R.L. Morris, D.R. Pittenger, D.A. Shaw, and D.F. Zoldoske. 2008. Efficient water use in residential urban landscapes. HortScience 43(7):2081-2092.

Kjelgren, R., L. Rupp, and D. Kjelgren. 2000. Water conservation in urban landscapes. HortScience 35(6):1037-1040.

Levitt, D.G., J.R. Simpson, and J.L. Tipton. 1995. Water use of two landscape trees in Tucson, Arizona. Journal of the American Society of Horticultural Science 120(3):409-416.
Montague, T., R. Kjelgren, R. Allen, and D. Webster. 2004. Water loss estimates for five recently transplanted tree species in a semi-arid climate. Journal of Environmental Horticulture 22(4):189-196.

Pittenger, D.R., J. Downer, D.R. Hodel, and M. Mochizuki. 2009. Estimating water needs of landscape palms in Mediterranean climates. HortTechnology 19(4):700-704.

Pittenger, D.R., D.A. Shaw, D.R. Hodel, and D.B. Holt. 2001. Responses of landscape groundcovers to minimum irrigation. Journal of Environmental Horticulture 19(2):78-84.

Pittenger, D.R., D.R. Hodel, and D.A. Shaw. 1990. Relative water requirements of six ground-cover species. HortScience 25(9):1085 (abstract).

Reid, S.K., and L.R. Oki. 2008. Field trials identify more native plants suited to urban landscaping. California Agriculture 62(3):97-104.

Sachs, R.M. 1991. Stress-adapted landscapes save water, escape injury in drought. California Agriculture 45(6):19-21.

Santos, M., and D. Burger. 1995. Bibliography of Literature on Landscape Water Conservation and Management. Sacramento, California: California Landscape Contractors Association. 99 p.

Schuch, U.K., E. Martin, T. Mahato, and J. Subramani. 2010. Effect of irrigation frequency on arid-adapted landscape trees. ASHS (abstract).

Schuch, U.K., and D.W. Burger. 1997. Water use and crop coefficients of woody ornamentals in containers. Journal of the American Society of Horticultural Science 122(5):727-734.

Shaw, D.A., and D.R. Pittenger. 2004. Performance of landscape ornamentals given irrigation treatments based on reference evapotranspiration. Acta Horticulturae 664:607-613.

Staats, D., and J.E. Klett. 1995. Water conservation potential and quality of non-turf groundcovers versus Kentucky bluegrass under increasing levels of drought stress. Journal of Environmental Horticulture 13(4):181-185.

\section{Laurence Costello}

146 Jordan Ave.

San Francisco, California 94118, U.S.

Zusammenfassung. Hier wird eine Literaturübersicht zum Thema Wasserbedarf und Wasserverlust von Landschaftspflanzen vorgestellt. Feldversuche mit Lysimetern und in Containern werden zusammengefasst und diskutiert. In einigen Studien sind die Ertragskoeffizienten oder Wasserverbrauchkoeffizienten eingeschlossen. Es wird hier ein Diskussion zum Thema der vorgefundenen Bandbreite in den Forschungsmethoden vorgestellt sowie auf den Bedarf nach einem standartisierten Protokoll für Wasserbedarfsstudien hingewiesen.

Resumen. Se presenta una revisión de literatura sobre las necesidades hídricas y la pérdida de agua de las plantas en el paisaje. Se resumen y comentan los estudios realizados en el campo, usando lisímetros y contenedores. En algunos estudios se incluyen los coeficientes de cultivo o coeficientes de uso del agua. Se presenta un análisis de la variabilidad encontrada en los métodos de investigación y la necesidad de un protocolo estandarizado para los estudios de las necesidades de agua para el árbol. 